\title{
Anti-CD33 Monoclonal Antibody BI 836858
}

National Cancer Institute

\section{Source}

National Cancer Institute. Anti-CD33 Monoclonal Antibody BI 836858. NCI Thesaurus.

Code C116737.

An engineered, fully human, immunoglobulin (Ig) G1 anti-CD33 monoclonal antibody, with potential antineoplastic activity. Upon administration, anti-CD33 monoclonal antibody BI 836858 induces an antibody-dependent cellular cytotoxicity (ADCC) against CD33expressing tumor cells, leading to cell death. CD33, a cell surface antigen expressed on normal non-pluripotent hematopoietic stem cells, is overexpressed on myeloid leukemia cells. 